\title{
Plant growth promoting actinobacteria from rhizosphere soils of black pepper in Wayanad
}

\author{
Rineesha backera ${ }^{{ }^{*}}$, d. Girija ${ }^{1}$, Surendra gopal ${ }^{1}$, Reshmy Vijayaraghavan ${ }^{1}$ and Beenav. I ${ }^{1}$ \\ ${ }^{1}$ College of Horticulture, Kerala Agricultural University, Thrissur 680 656, Kerala, India. \\ *Corresponding Author: Rineesha backera. College of Horticulture, Kerala Agricultural University, Thrissur 680 656, Kerala, India. \\ Received date: March 08, 2021; Accepted date: June 15, 2021; Published date: June 21,2021 \\ Citation: backera R., Girija D., gopal S., Vijayaraghavan R. and Beenav I. (2021) Plant growth promoting actinobacteria from rhizosphere soils of \\ black pepper in Wayanad. J, Biotechnology and Bioprocessing 2(5); DOI: 10.31579/2766-2314/031
}

Copyright: (C) 2021, Rineesha backera. This is an open access article distributed under the Creative Commons Attribution License, which permits unrestricted use, distribution, and reproduction in any medium, provided the original work is properly cited.

\begin{abstract}
Actinobacteria isolated from the rhizosphere soils of black pepper comprising both flood affected and non-flood affected areas of Wayanad district. Among different soil samples analysed, Puttad (Ptd) recorded significantly superior actinobacterial population on starch casein aga, Kenknight \& Munaier's agar and actinomycetes isolation agar. Actinobacterial colonies could not be detected in any of the flooded soil samples on any medium, even at a dilution of $10^{-1}$, except in Meppadi soil, which recorded a low population of $0.3 \times 10^{1} \mathrm{cfu} \mathrm{g}^{-1}$ soil. Starch casein agar is best media to isolate actinobacteria from soil samples compared to other two media. The cultural, morphological and biochemical characterization of thirty-five isolates was carried out. Further the isolates were evaluated for their plant growth promoting traits such as IAA production, nitrogen fixation, $\mathrm{P}, \mathrm{K}$ and $\mathrm{Zn}$ solubilization. The isolates Ptd-A and Amb-C were found to be significantly superior to all other isolates, with IAA production of $15.9 \mathrm{~g} \mathrm{ml}^{-1}$ and $15.38 \mathrm{~g} \mathrm{ml}^{-1}$ respectively. The four isolates viz. Ptd-A, Ptd-E, Ptd-B and Ptr-A recorded significantly superior nitrogen fixation and the phosphate solubilized was significantly higher in Ptd-E, Ptd-D, Ptr-E, Ptd-A and Ptr-A, as compared to other isolates. All isolates were negative to $\mathrm{K}$ and $\mathrm{Zn}$ solubilization. Based on in vitro evaluations, three isolates were shortlisted (Ptd-A, Ptd-E and PtrA) and subjected to in vivo evaluation for growth promotion in black pepper (variety Panniyur 1). Rooted plants of black pepper were raised in sterile potting mixture. Bioinoculants applied at the time of planting and 45 days after planting. The PGPR Mix-1 and Organic Package of Practices Recommendations (2017) were used for comparison with the microbial inoculants along with control. In the in-planta experiment, biometric characters were recorded at monthly intervals, up to five months. The actinobacterial treatment, $\mathrm{T}_{1}$ : Ptd-E, $\mathrm{T}_{2}$ : Ptd-A and $\mathrm{T}_{3}$ : Ptr-A showed significant increase in shoot length, number of leaves and internode length throughout the growth period from planting to five MAP. Significantly higher root growth was observed in treatment $\mathrm{T}_{2}$ : Ptd-A, with significantly higher root volume, fresh and root weight. The potential actinobacteria were identified Ptd-A and Ptr-A as Streptomyces sp. and Ptd-A as Actinobacteria bacterium using 16S r RNA gene sequencing.
\end{abstract}

Keywords: black pepper, actinobacteria, growth promotion, PGPR, rhizosphere

\section{Introduction}

Effective farming practices, now a days, rely on extensive use of chemical fertilizers in order to enhance plant growth and yield. Excessive use of chemical fertilizers to increase production from available land has resulted in deterioration of soil quality. The use of chemical fertilizers is not only costly but also hazardous for both the environment and humans. In addition, manufacturing of such fertilizers depletes non-renewable natural resources. An increasing demand for low-input agriculture has resulted in a greater interest in soil microorganisms which are able to enhance the plant nutrition, health and soil quality (Jeffries et al., 2003).

Actinomycetes are one of the major components of rhizosphere microbial populations and are useful in soil nutrient cycling as well as plant growthpromotion (PGP) (Merzaeva et al., 2006). Actinomycetes are the most widely distributed group of microorganisms well known for their saprophytic survival (Takizawa et al., 1993). Among them, the genus Streptomyces are the ma- jor sources of many biologically active compounds having antifungal, antibacterial and plant growth promoting sub- stances (Khamna et al., 2009; Suzuki et al., 2000). They mostly colonize the rhizosphere and rhizo- plane and enhance plant growth is either by direct stimulation such as iron chelation, phosphate solubilization, nitrogen fixation and phytohormone production or by indirect stimulation such as suppression of plant pathogens and induction of systemic resistance in host plants (Panhwar et al., 2012). Despite the well-documented history of Streptomyces in biocontrol and plant growth promotion they have been rarely exploited for their PGPR potential.

Black pepper is an important spice crop of Kerala. In India, Kerala ranks first in black pepper production, contributing about $97 \%$ of the total production and Wayanad is one of the main pepper growing tracts in Kerala, with an area of 10565 ha and production of 4136 tonnes (GoK, 2017). Black pepper production in Wayanad is declining year after year mainly due to the poor soil health status, improper land management practices, with changes in climatic factors leading to the incidence of biotic and abiotic stresses.

In the present study, actinobacteria isolated from rhizosphere soils of 
black pepper were characterized and evaluated for PGP properties. The promising strains were also evaluated for their PGP in black pepper under in planta.

\section{Materials and methods}

\section{Collection of rhizosphere soil samples}

Rhizosphere soil samples are collected from five different locations of flood affected and non- flood affected black pepper growing areas of Wayanad districts. The soil samples were collected using quartering technique. Global Positioning System (GPS) reading of the location was recorded. About 100g soils from each location collected in polythene bag, labelled, sealed and stored in refrigerator till further studies.

\section{Isolation of actinobacteria}

Isolation and enumeration of actinobacteria from rhizosphere soil samples was carried out by serial dilution and plating technique (Johnson and curl, 1972).

Ten gram of soil sample was mixed in $90 \mathrm{ml}$ sterile water and the contents were mixed thoroughly by shaking for five minutes. One $\mathrm{ml}$ of aliquot was transferred to $9 \mathrm{ml}$ water blank and serially diluted to a final dilution of $10^{-3}$ and $10^{-4}$ for non- flood affected areas and $10^{-1}$ for flood affected areas. The $1 \mathrm{ml}$ of suspension from respective dilutions was transferred aseptically into petri dishes. Twenty $\mathrm{ml}$ of molten and cooled agar of actinomycetes isolation agar, Kenknight Munaier's agar and starch casein agar media were poured into petri plates. The plates were rotated clockwise and anti-clockwise direction and allowed to solidify. Three replicates were used for each media. Plates were incubated at $28^{\circ} \mathrm{C}$ for 5 12 days. Number of colonies on the respective media was calculated and expressed as colony forming units per gram of soil (cfu/g).

\section{Characterization of isolates}

\section{Morphological and cultural characterization}

The actinobacteria were grown in Kenknight's agar media at $28^{\circ} \mathrm{C}$ for 7 days. The characters such as colony appearance, type of aerial hyphae was observed. The colour of spore masses and diffusible pigment production were visualized. Gram's staining (Hucker and conn, 1923) was done and gram reaction and spore chain morphology of the isolates were observed under microscope.

\section{Biochemical characterization}

\section{Oxidase test}

The isolates were smeared on oxidase disc (Hi-media DD018-1VL). Appearance of violet colour within 5-10 seconds at $25-30{ }^{\circ} \mathrm{C}$ indicated positive reaction. A colour change after 60 seconds or no colour change considered as negative.

\section{Catalase test}

Smear of the isolates prepared in a clean glass slides and a drop of hydrogen peroxide (3\%) was added it. Cultures which immediately showed effervescence were treated as positive (Taylor and Achanzar, 1972).

\section{Utilization of sugars}

Fermentation broths (glucose, fructose and sucrose) was prepared in test tubes. A durham's tube was placed in an inverted position into the broth. The isolates were inoculated in broth and uninoculated control. The three replication is maintained and incubated for $37^{\circ} \mathrm{C}$ for 5 days. A change in colour from red to yellow and appearance of bubbles indicated positive for fermentation tests (Cowan, 1974).

In vitro screening for plant growth promoting (PGP) activities
All the isolates were screened for plant growth promoting activities like indole acetic acid (IAA) production, nitrogen fixation, phosphate solubilization, potash solubilization and zinc solubilization under in vitro conditions.

\section{Screening of actinobacterial isolates for IAA production}

The actinobacteria isolates were screened for the production of IAA (Ahmed et al., 2008). All isolates were inoculated in sterile Luria-Bertani supplemented with tryptophan at the rate of $1 \mathrm{mg} \mathrm{ml}^{-1}$. The tubes were incubated for 7 days in the dark. The cultures were centrifuged at 3000 rpm for 30 minutes and the supernatant was collected. $4 \mathrm{ml}$ Salkowski reagent was added to the supernatant. The pink colour development indicated positive for IAA production. The pink colour developed test tubes were measured for optical density at $530 \mathrm{~nm}$ using a spectrophotometer. The OD values were plotted on a standard graph to obtain the quantity of IAA produced by the isolates and expressed as microgram per millilitre of broth.

\section{Screening of actinobacterial isolates for nitrogen fixation}

The thirty-five isolates were streaked on $\mathrm{N}$-free Jensen's agar media. The inoculated plates were then incubated at $28 \pm 2{ }^{\circ} \mathrm{C}$ for six days. The actinobacterial isolates which were able to grow on $\mathrm{N}$ free media considered as nitrogen fixers. Based on the growth in the media, nitrogen fixers were rated as high (+++), medium $(++)$, poor (+) and no growth () .

\section{Estimation of nitrogen fixation}

Nitrogen fixation by the thirty-five isolates were quantified by microKjeldahl method (Jackson, 1973 and Bremner, 1960).

$\mathrm{mg}$ of $\mathrm{N} / \mathrm{g}$ of C source $=\frac{\mathrm{TV}-\mathrm{BV} \times \mathrm{N} \times 0.014 \times 1000}{\mathrm{Y}}$

Where,

$\mathrm{TV}=$ Titre value

$\mathrm{BV}=$ Blank value

$\mathrm{N}=$ Normality of $\mathrm{H}_{2} \mathrm{SO}_{4}$

$\mathrm{Y}=$ Weight of carbon source

Screening of actinobacterial isolates for phosphate, potassium and zinc solubilization

The thirty-five isolates obtained were screened for phosphate solubilization on Pikovskaya's agar media (Nguyen et al., 1992), potash solubilization on Aleksandrow's agar media (Nguyen et al., 1992).and zinc solubilization on mineral salt agar media amended with $0.1 \%$ of insoluble zinc oxide (Venkatakakrishnan et al., 2004). Incubated for five to seven days at $28 \pm 2{ }^{\circ} \mathrm{C}$. The halo zone and colony diameter were measured after seven days of incubation. The ability to solubilize was expressed as per cent solubilization efficiency (SE)

Solubilizing efficiency $(\%$ SE $)=$ SD x 100

\section{$\mathrm{CD}$}

SD - Solubilization diameter $(\mathrm{mm})$

$\mathrm{CD}$ - Colony diameter $(\mathrm{mm})$

\section{Estimation of phosphate solubilization by actinobacterial isolates}

The isolates which showed positive reaction for phosphorus solubilization on Pikovskaya's agar containing tricalcium phosphate in the preliminary screening were further subjected to quantification of phosphorus solubilization using phospho-molybdic blue colour method (Olsen et al., 
1962).

\section{Molecular characterization}

The selected actinobacteria were sent to Rajiv Gandhi Centre for Biotechnology, Trivandrum for identification by $16 \mathrm{~S}$ rRNA sequence analysis. The sequences obtained from RGCB were compared with similar sequences from NCBI, compared using the BLAST program. The sequences of isolates were submitted to GenBank of NCBI and accession numbers obtained.

\section{Evaluation of actinomycetes strains under greenhouse conditions}

Preparation of Actinomycete inoculum

In this experiment, the threes short listed actinobacteria strains viz. Ptd-A, Ptd-E and Ptr-A were inoculated in Kenknight Munaeir's broth $(100 \mathrm{ml})$ and incubated for 10 days. After incubation, the broth culture was mixed with talc in the ratio of 1:3. The formulation diluted and adjusted the cfu to $10^{8} \mathrm{~g}^{-1}$.

In planta evaluation of selected isolates in black pepper

The three most promising and efficient isolates were evaluated under sterile potting mixture for their growth promotion efficiency in black pepper. The experiment was conducted during May to October 2020 in the net house of Department of Agricultural Microbiology, Vellanikkara. The pot experiment was conducted with one month old rooted Panniyur 1 variety. Before planting, the uprooted plants were measured for initial growth parameters. The plants were then transplanted into polybags (16X12) filled with potting mixture (sand: soil: FYM 1:1:1). There were six treatments with three replications in CRD with four plants/polybag and four polybags/replications. The treatments were $\mathrm{T}_{1}$ - Ptd-E; $\mathrm{T}_{2}$ - Ptd-A; $\mathrm{T}_{3}-$ Ptr-A; T4- PGPR Mix-1; T5-organic POP (2017) and $\mathrm{T}_{6}$ - Control. The inoculant applied as soil drenching and foliar application $2 \%$ at the time of planting and 45 days after planting.

\section{Statistical Analysis}

Analysis of variance was done on the data collected using the statistical package WASP 2.0. (Gomez and Gomez, 1984).

\section{Results and discussion}

The present study is an attempt to identify strains of potential plant growth promoting actinobacteria from flood affected and non-flood affected rhizosphere soils of black pepper in Wayanad (Table 1).

\begin{tabular}{|l|l|l|l|}
\hline \multicolumn{1}{|c|}{ Location } & Code & latitude & Longitude \\
\hline Non-flooded & Ptd & 11.57843 & 76.17174 \\
\hline Puttad & Amb & 11.61970 & 76.21059 \\
\hline Ambalavayal & Vlt & 11.79405 & 75.90547 \\
\hline Valat & Ptr & 11.8434 & 76.17174 \\
\hline Pathiri & Plp & 11.79213 & 76.16624 \\
\hline Pulpally & Vlm & 75.93748 \\
\hline Flooded & Vth & 11.7359 & 76.04021 \\
\hline Vellamunda & Pnm & 11.55097 & 76.07398 \\
\hline Vythiri & Adk & 11.73779 & 76.18896 \\
\hline Panamaram & Mpd & 11.55514 & 76.13529 \\
\hline Adikkolly & \multicolumn{1}{|l|}{} \\
\hline Meppadi &
\end{tabular}

Table 1. Details of soil sample collections

In this study, Ten soil samples consisting of five from non-flood affected and five from flood affected black pepper gardens in Wayanad district were assessed for actinobacterial population. Enumeration was carried out on three different media viz. Kenknight Munaier's agar, Actinomycete isolation agar and starch casein agar. Different media attempted because any single medium may not be optimum for actinobacteria present in the soil. It was also expected to assess the morphology of actinobacterial colonies on different media. Among different soil samples analysed, Puttad (Ptd) recorded significantly superior actinobacterial population on all the three media. The population of Ambalavayal soil was also significantly higher on starch casein agar. Lowest population was observed in Pathiri (Ptr) sample on Kenknight \& Munaier's agar and actinomycetes isolation agar (Table 2). Actinobacterial colonies could not be detected in any of the flooded soil samples on any medium, even at a dilution of $10^{-1}$, except in Meppadi soil, which recorded a low population of $0.3 \times 10^{1} \mathrm{cfu}$ g- 1 soil.

One of the reasons for the absence of actinobacteria in flooded soils could be the limited entry of atmospheric oxygen during flooding, which could have brought about physical, chemical and biological consequences for soil habitats and species (Graff and Conrad, 2005). Bassio and Scow (1995) reported that flooding caused a decrease in the metabolically active microbial diversity, using BIOLOG microplates. Flooding led to a decline in the availability of suitable electron acceptors resulting in lower rates of organic matter decomposition (Bassio and Scow, 1995).

\begin{tabular}{|c|c|c|c|c|}
\hline \multicolumn{2}{|c|}{ 1. Non floode areas } \\
\hline \multirow{2}{*}{ Location } & \multirow{2}{*}{ Code } & \multicolumn{3}{|c|}{ Population of actinobacteria $\left(10^{4}\right)$ cfu g $^{-1}$} \\
\cline { 3 - 5 } & P1 & $7(0.84)^{\mathrm{a}}$ & $6.67(0.82)^{\mathrm{a}}$ & Kenknigt's agar $^{\mathrm{b}}$ \\
\hline Puttad & P2tinomycetes isolation agar & $12(1.08)^{\mathrm{a}}$ \\
\hline Ambalavayal & $5(0.59)^{\mathrm{b}}$ & $3(0.48)^{\mathrm{b}}$ & $70.84)^{\mathrm{a}}$ \\
\hline Valat & P3 & $3(0.48)^{\mathrm{b}}$ & $2(0.30)^{\mathrm{c}}$ & $4.330 .63)^{\mathrm{c}}$ \\
\hline Pathiri & P4 & $2(0.30)^{\mathrm{c}}$ & $1(0.00)^{\mathrm{d}}$ & $2.67(0.42)^{\mathrm{d}}$ \\
\hline Pulpally & P5 & $3(0.46)^{\mathrm{bc}}$ & $3(0.48)^{\mathrm{b}}$ & $2(0.30)^{\mathrm{e}}$ \\
\hline
\end{tabular}

Log transformed value in parantheses 
Cultural, morphological, biochemical and physiological characters were used for characterization and identification of thirty-five isolates of actinobacteria following Bergey's Manual of Determinative Bacteriology (Breed et al., 1948). The isolates varied in their colony morphology, colour of aerial mycelium and pigment production. The colour of aerial mycelium varied from dark brown to light brown, white, purple or green. Colonies were circular or irregular, with the exception of Amb-A and Plt$\mathrm{A}$, which were filamentous, and Plp-A and Plp-C which were rhizoid. The elevation, form and margin of colonies varied among the isolates. Morphological characterization of the actinobacterial isolates by different parameters such as spore chain morphology, spore colour, spore shape and spore surface ornamentation are essential for classification of the actinobacteria (Kumar et al., 2011). Two isolates Vlt-K and Plp-B produced yellow water-soluble pigment and Vlt-I produced water- insoluble purple pigment. Li et al. (2016) reported that actinobacteria produce two type of pigments water-soluble pigment or diffusible pigment and fat-soluble pigment or non-diffusible pigment.

The spore chain morphology varied among the genera and 14 isolates produced rectiflexibile type of sporulating aerial hypae ie. Straight or flexuous spore chains, partly in fascicles. Six isolates each formed spira type, short chain and closed spira of sporulating aerial hyphae. Single spore, sporangia formation and filamentous type of aerial hyphae were observed in one isolate each (Fig 1). Anusree and Bhai (2017) also categorized actinobacterial spore chains as rectiflexibiles, spira, retinaculiaperti, fragments, short chain, sporangia etc. as observed under the light microscope. Gram staining shows that actinobacteria are Gram positive in nature.

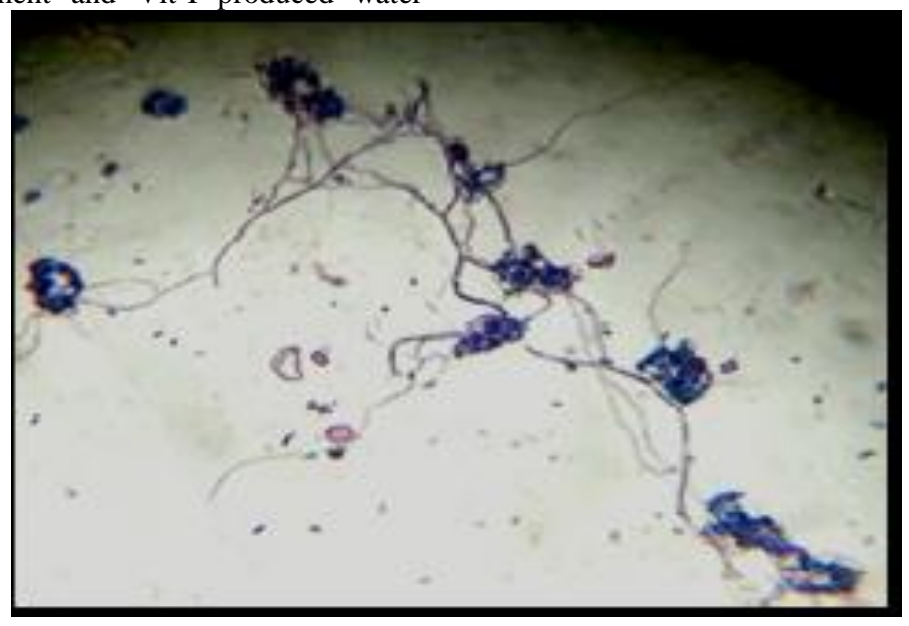

Figure 1. Spore chain morphology of Ptr-A

The ability of 35 actinobacterial isolates to ferment sugars and produce acids from various carbohydrate sources such as glucose, sucrose and fructose was tested. Three isolates (Ptd-A, Vlt-B and Vlt-G) produced a colour change of the broth from red to yellow, without any gas formation, which indicated that they are positive to glucose fermentation test and all the 35 isolates failed to utilize fructose and sucrose. The result of the present study indicated that actinobacteria are highly non-specific in their carbon requirements. Strzelczyk (1981) also reported the non-specificity of actinobacteria for carbon requirements. The present study also revealed that the isolates varied in their response to catalase and oxidase. The 26 isolates were positive to catalase test --and 13 isolates produced purple colour on the oxidase disc, indicating positive reaction to oxidase test.

In the present study, 35 actinobacteria isolates were screened for IAA production on the basis of development of pink colour in presence of tryptophan. All 35 isolates found to be positive in the preliminary screening for IAA production were used for quantitative estimation under in vitro. IAA production varied with isolates from $0.43 \mathrm{~g} \mathrm{ml}^{-1}$ to $15.9 \mathrm{~g}$ $\mathrm{ml}^{-1}$ (Fig 2 and Table 3). The isolates Ptd-A and Amb-C were found to be significantly superior to all other isolates, with IAA production of $15.9 \mathrm{~g}$ $\mathrm{ml}^{-1}$ and $15.38 \mathrm{~g} \mathrm{ml}^{-1}$ respectively. Similar study conducted by Suksaaid et al. (2017) reported that $51 \%$ of the mangrove actinobacterial isolates produced IAA in the range of $0.21 \mathrm{~g} \mathrm{ml}^{-1}$ to $165.74 \mathrm{~g} \mathrm{ml}^{-1}$.

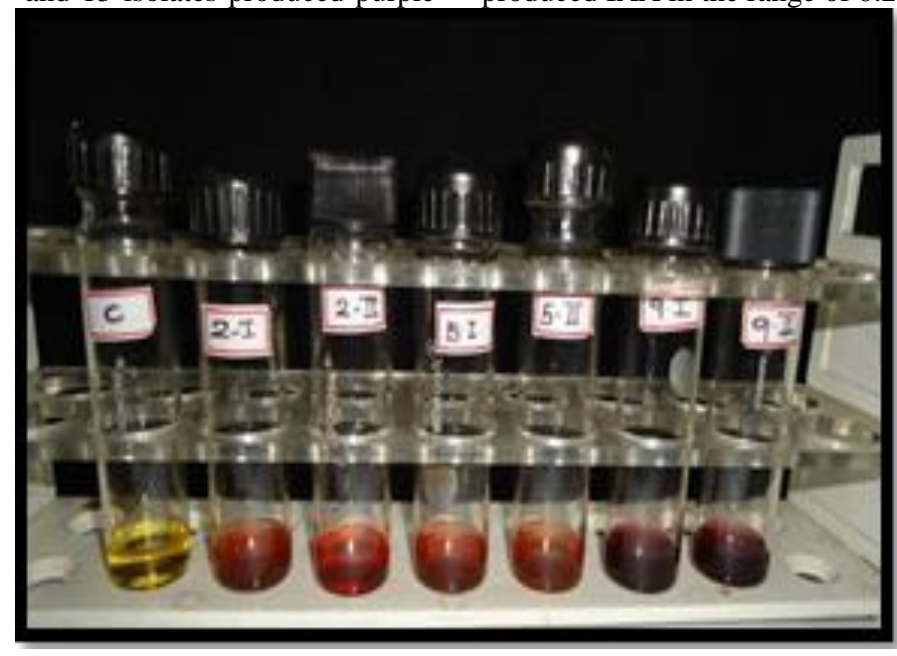




\begin{tabular}{|c|c|c|}
\hline $\begin{array}{c}\text { Sl. } \\
\text { No. }\end{array}$ & Isolates & $\begin{array}{c}\text { Concentration of } \\
\text { IAA }\left(\boldsymbol{\mu g} \mathbf{~ m l}^{-1}\right)\end{array}$ \\
\hline 1 & Ptd-A & $15.9(1.32)^{\mathrm{a}}$ \\
\hline 2 & Ptd-B & $2.97(0.90)^{\mathrm{ijkl}}$ \\
\hline 3 & Ptd-C & $1.19(0.79)^{\mathrm{pqr}}$ \\
\hline 4 & Ptd-D & $3.27(0.92)^{\mathrm{hij}}$ \\
\hline 5 & Ptd-E & $13.53(1.27)^{\mathrm{b}}$ \\
\hline 6 & Amb-A & $6.35(1.055)^{\mathrm{f}}$ \\
\hline 7 & Amb-B & $0.43(0.74)^{\mathrm{st}}$ \\
\hline 8 & Amb-C & $15.38(1.31)^{\mathrm{a}}$ \\
\hline 9 & Amb-D & $2.23(0.86)^{\mathrm{mn}}$ \\
\hline 10 & Amb-E & $1.76(0.83)^{\mathrm{nop}}$ \\
\hline 11 & Amb-F & $8.47(1.13)^{\mathrm{d}}$ \\
\hline 12 & Amb-G & $1.49(0.81)^{\mathrm{op}}$ \\
\hline 13 & Amb-H & $2.01(0.85)^{\mathrm{mno}}$ \\
\hline 14 & Vlt-A & $3.17(0.91)^{\mathrm{hijk}}$ \\
\hline 15 & Vlt-B & $4.14(0.96)^{\mathrm{g}}$ \\
\hline 16 & Vlt-C & $2.52(0.88)^{\mathrm{klm}}$ \\
\hline 17 & Vlt-D & $1.56(0.82)^{\mathrm{op}}$ \\
\hline 18 & Vlt-E & $3.8(0.94)^{\mathrm{h}}$ \\
\hline 19 & Vlt-F & $2.05(0.85)^{\mathrm{mno}}$ \\
\hline 20 & Vlt-G & $2.3(0.86)^{\mathrm{lmn}}$ \\
\hline 21 & Vlt-H & $2.55(0.88)^{\mathrm{jklm}}$ \\
\hline 22 & Vlt-I & $2.7(0.89)^{\mathrm{ijklm}}$ \\
\hline 23 & Vlt-J & $0.32(0.73)^{\mathrm{t}}$ \\
\hline 24 & Vlt-K & $7.18(1.09)^{\mathrm{def}}$ \\
\hline 25 & Vlt-L & $4.35(0.97)^{\mathrm{g}}$ \\
\hline 26 & Ptr-A & $11.22(1.21)^{\mathrm{c}}$ \\
\hline 27 & Ptr-B & $0.86(0.77)^{\mathrm{grs}}$ \\
\hline 28 & Ptr-C & $3.31(0.92)^{\mathrm{hi}}$ \\
\hline 29 & Ptr-D & $7.93(1.11)^{\mathrm{de}}$ \\
\hline 30 & Ptr-E & $4.1(0.96)^{\mathrm{g}}$ \\
\hline 31 & Ptr-F & $1.37(0.80)^{\mathrm{pq}}$ \\
\hline 32 & Plp-A & $6.96(1.08)^{\mathrm{ef}}$ \\
\hline 34 & Plp-B & $0.72(0.76)^{\mathrm{rst}}$ \\
\hline & Plp-C & $1.17(0.79)^{\mathrm{pqr}}$ \\
\hline Mpd-A & $6.64(1.07)^{\mathrm{f}}$ \\
\hline
\end{tabular}

Table 3. IAA production by actinobacterial isolates under in vitro conditions

In the present study, thirty-five actinobacterial isolates were positive to qualitative screening for nitrogen fixation in $\mathrm{N}$-free medium. Seven isolates were further selected based on their growth on $\mathrm{N}$ free medium. Among the seven selected isolates, four isolates viz. Ptd-A, Ptd-E, Ptd-B and Ptr-A recorded significantly superior nitrogen fixation of $24.7 \mathrm{mg}$ (by
Ptd-A and Ptd-E), $23.3 \mathrm{mg}$ (Ptd-B) and $22.87 \mathrm{mg}$ per gram of sucrose utilized (Ptr-A) (Table 4). In a report by Tokala et al. (2002), nitrogen fixation in roots of young pea seedlings with symbiotic Rhizobium sp. was observed to be promoted by Streptomyces lydicus strain WYEC108.

\begin{tabular}{|c|c|}
\hline Isolates & $\begin{array}{l}\text { Amount of nitrogen fixed } \\
\text { (mg of } \mathbf{~ g}^{-\mathbf{1}} \text { of } \mathbf{C} \text { utilised) }\end{array}$ \\
\hline Ptd-A & $24.70^{\mathrm{a}}$ \\
\hline Vlt-C & $19.74^{\mathrm{c}}$ \\
\hline Ptr-C & $19.97^{\mathrm{bc}}$ \\
\hline Ptd-E & $24.70^{\mathrm{a}}$ \\
\hline Ptd-B & $23.30^{\mathrm{a}}$ \\
\hline Amb-B & $20.11^{\mathrm{bc}}$ \\
\hline Ptr-A & $22.87^{\mathrm{ab}}$ \\
\hline
\end{tabular}

Table 4. Nitrogen fixation by selected actinobacterial isolates

In the present study, among 35 isolates only six were positive to preliminary screening for phosphate solubilization efficiency by the formation of clear zone on Pikovskaya's agar medium. The estimation of phosphate solubilization revealed that the amount of phosphate solubilized was significantly higher in Ptd-E (40.74 $\mathrm{g} \mathrm{ml}^{-1}$ ), Ptd-D (40.46 $\left.\mathrm{g} \mathrm{ml}^{-1}\right)$, Ptr-E (40.09 $\left.\mathrm{g} \mathrm{ml}^{-1}\right)$, Ptd-A (39.64 $\left.\mathrm{g} \mathrm{ml}^{-1}\right)$ and Ptr-A (38.89 $\mathrm{g} \mathrm{ml}^{-}$ ${ }^{1}$ ), as compared to the isolate Ptd-B, which solubilized $31.55 \mathrm{~g} \mathrm{ml}^{-1}$ (Table 5). Various genera of actinomycetes such as Rhodococcus, Arthrobacter, Streptomyces, Gordonia and Micromonospora were reported to have Psolubilization potential under laboratory and glasshouse conditions (Jog 
et al., 2014). Prada et al. (2014) isolated 57 strains of actinobacteria and estimated phosphorus solubilization ability, which ranged from 8.7 to $118.4 \mathrm{mg} / \mathrm{kg}$ and $\mathrm{pH}$ from 4.0 to 5.9. Productions of various organic acids such as gluconic acid, citric acid, malic acid, lactic acid, propionic acid, oxalic and succinic acids by actinomycetes are believed to be the mechanism of their phosphate solubilisation, which also results in reduction of $\mathrm{pH}$ of the media (Hamdali et al., 2010) (Table 5).

\begin{tabular}{|c|c|c|}
\hline Isolates & $\begin{array}{c}\text { Quantity of P- } \\
\text { solubilized ( } \begin{array}{c}\mathbf{- 1} \\
\mathbf{m l}^{-1}\end{array}\end{array}$ & $\begin{array}{c}\text { Reduction in } \\
\mathbf{p H}\end{array}$ \\
\hline Ptd-A & $39.64^{\mathrm{a}}$ & 6.0 \\
\hline Ptd-D & $40.46^{\mathrm{a}}$ & 5.7 \\
\hline Ptd-E & $40.74^{\mathrm{a}}$ & 5.7 \\
\hline Ptd-B & $31.55^{\mathrm{b}}$ & 6.1 \\
\hline Ptr-A & $38.89^{\mathrm{a}}$ & 6.0 \\
\hline Ptr-E & $40.09^{\mathrm{a}}$ & 5.8 \\
\hline
\end{tabular}

\section{Table 5. Quantitative estimation of Phosphate solubilization by selected isolates}

In the present study, none of the isolates exhibited the ability for potassium and zinc solubilization. Nafis et al. (2019) reported that currently, little information is available on potassium solubilization by rhizospheric actinobacteria. Among 80 isolates, only two strains (Agrobacterium tumefaciens and Rhizobium sp.) produced clear halo zone around their colonies in solid medium supplemented with zinc oxide $0.1 \%$.
The three most efficient isolates of actinobacteria were selected based on their ability to produce indole acetic acid, fix nitrogen, and solubilize phosphorus, potassium and zinc. The isolates were identified by $16 \mathrm{~S}$ rRNA sequencing. The selected actinobacterial isolates were Ptd-E (Actinobacteria bacterium), Ptd-A (Streptomyces sp.) and Ptr-A (Streptomyces sp.). The sequences were deposited in the NCBI data base with Gene bank Accession nos. as given in Table 6.

\begin{tabular}{|c|c|c|c|}
\hline SI. No & Isolates & Location & Accession \\
\hline 1 & Ptd-A: Streptomyces sp. & Puttad & MW534685 \\
\hline 2 & Ptd-E: Actinobacteria bacterium & Puttad & MW534690 \\
\hline 3 & Ptr-A: Streptomyces sp. & Pathiri & MW534694 \\
\hline
\end{tabular}

Table 6. Gene bank accession numbers

After in vitro screening of isolates, the plant growth promoting activities were evaluated in sterile soil in with black pepper (variety Panniyur 1) as the test crop. The treatments included the three most efficient isolates (Ptd-E, Ptd-A and Ptr-A), the fourth treatment comprised PGPR mix-1 (commercial formulation of KAU). Organic Package of Practices Recommendations (2017) were used for comparison with the microbial inoculants along with control. Actinobacteria were made into talc-based formulation and applied at the time of planting and 45 days after planting.

In the in-planta experiment, biometric characters were recorded at monthly intervals, up to five months. The actinobacterial treatment, $\mathrm{T}_{1}$ : Ptd-E (Actinobacteria bacterium), $\mathrm{T}_{2}$ : Ptd-A (Streptomyces sp.) and $\mathrm{T}_{3}$ : Ptr-A (Streptomyces sp.) showed significant increase in shoot length, number of leaves and internode length throughout the growth period from planting to five MAP (Fig 3 and Table 7).

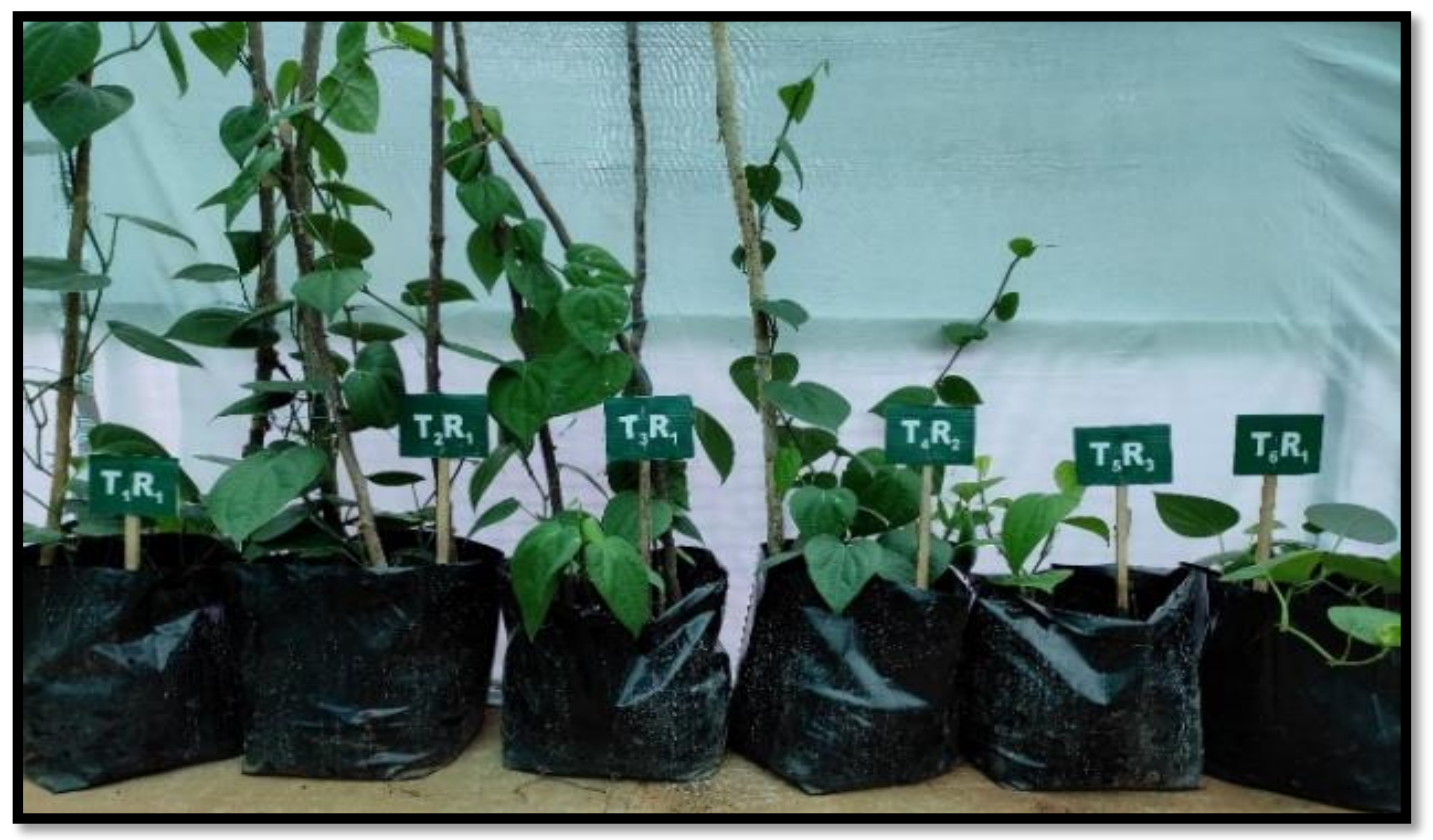


Significantly higher root growth was observed in treatment $\mathrm{T}_{2}$ : Ptd-A (Streptomyces $\mathrm{sp}$.), with significantly higher root volume, fresh and root weight (Fig 4 and Table 7). This isolate was found to be the most efficient IAA producer and good phosphate solubilizer also. Many studies revealed that combination of IAA production and phosphate solubilization by microbes in soil promote plant growth. In vitro evaluation by inoculating the roots with PGPR has revealed that many PGPR may reduce the growth rate of the primary root (Dobbelaere et al., 1999), increase the number and length of lateral roots (Combes-Meynet et al., 2011; Chamam et al., 2013), and stimulate root hair elongation in vitro (Dobbelaere et al., 1999; Contesto et al., 2008)

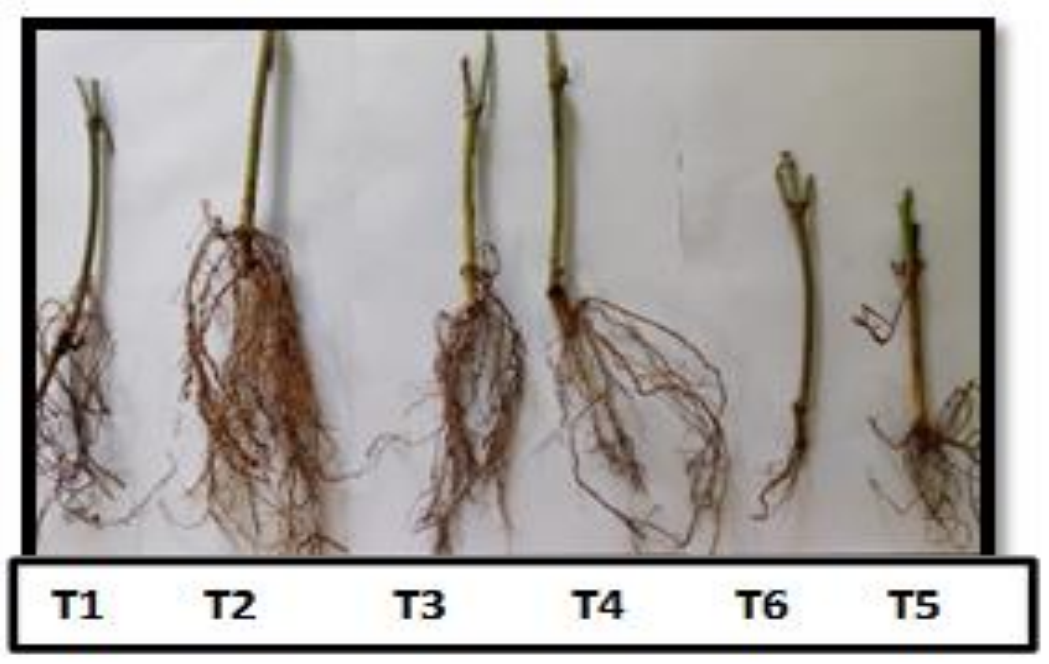

Figure 4. Root architecture on different treatment

\begin{tabular}{|c|c|c|c|c|c|c|}
\hline Treatments & $\begin{array}{c}\text { Fresh root wt. } \\
(\mathbf{g})\end{array}$ & $\begin{array}{c}\text { Dry root wt } \\
(\mathbf{g})\end{array}$ & $\begin{array}{c}\text { Root volume } \\
(\mathbf{m l})\end{array}$ & Shoot length & No. of nodes & No of leaves \\
\hline T1-Ptd-E & $3.29^{\mathrm{bc}}$ & $0.80^{\mathrm{bc}}$ & $2.59^{\mathrm{b}}$ & $70.82^{\mathrm{a}}$ & $5.85^{\mathrm{ab}}$ & $13.42^{\mathrm{a}}$ \\
\hline T2-Ptd-A & $4.31^{\mathrm{a}}$ & $1.23^{\mathrm{a}}$ & $3.54^{\mathrm{a}}$ & $77.49^{\mathrm{a}}$ & $6.47^{\mathrm{a}}$ & $15.01^{\mathrm{a}}$ \\
\hline T3-Ptr-A & $3.75^{\mathrm{ab}}$ & $0.92^{\mathrm{b}}$ & $2.69^{\mathrm{b}}$ & $74.75^{\mathrm{a}}$ & $6.32^{\mathrm{a}}$ & $14.04^{\mathrm{a}}$ \\
\hline T4 - PGPR Mix 1 & $2.81^{\mathrm{cd}}$ & $0.70^{\mathrm{c}}$ & $1.99^{\mathrm{bc}}$ & $52.53^{\mathrm{b}}$ & $5.83^{\mathrm{ab}}$ & $9.62^{\mathrm{b}}$ \\
\hline $\begin{array}{c}\text { T5 - Organic POP } \\
(2017)\end{array}$ & $2.21^{\mathrm{d}}$ & $0.64^{\mathrm{cd}}$ & $1.75^{\mathrm{cd}}$ & $47.61^{\mathrm{b}}$ & $5.16^{\mathrm{bc}}$ & $8.91^{\mathrm{b}}$ \\
\hline T6- Control & $1.52^{\mathrm{e}}$ & $0.51^{\mathrm{d}}$ & $1.25^{\mathrm{d}}$ & $32.25^{\mathrm{c}}$ & $4.73^{\mathrm{c}}$ & $5.47^{\mathrm{c}}$ \\
\hline
\end{tabular}

Table 7. Effect of individual of actinobacteria in black pepper growth promotion (five months after planting)

Among three most potential plant growth promoting actinobacteria were selected, all actinobacterial isolates are efficient for promoting plant growth. These isolates may further be evaluated under field conditions for plant growth promotion, disease suppression and drought tolerance ability. The compatibility of the actinobacteria with other plant growth promoting microorganisms and chemical fertilizers may also be evaluated. In addition, expansion of local production models for commercialization of these microbial inoculants is also essential. Only little information is available on potassium and zinc solubilizing actinobacteria and therefore further studies are required in this field. Many of the actinobacterial genera have not been exploited for agricultural, biotechnological or industrial purposes.

\section{Conclusions}

The three actinobacteria from black pepper rhizosphere Ptd-A, Ptd-E and Ptr-A were found to be effective for enhancing plant growth. The 16SrDNA gene sequence analysis showed Ptd-A and Ptr-A are Streptomyces sp. and Ptd-E are Actinobacteria bacterium.

\section{Acknowledgement}

The authors are thankful to the Department of Agricultural Microbiology, College of Horticulture, Vellanikkara for providing necessary facilities and support. The financial support from Kerala Agricultural University, Vellanikkara is deeply acknowledged.

\section{Reference}

1. Ahmad, F., Ahmad, A. I., and Khan, M. S. (2008) Screening of free-living rhizospheric bacteria for their multiple plant growth promoting activities. Microbiol. Res. 163, 173-181.

2. Anusree, T. and Bhai, S. (2017) Distribution, diversity and antagonistic actinobacteria from black pepper rhizosphere. $J$. Glob. Biosci. 6(10): 5260-5288.

3. Bossio D.A. Scow K.M. (1995) Impact of carbon and flooding on the metabolic diversity of microbial communities in soils. Appl. Environ. Microbiol. 61, 4043-4050

4. Cowan, S. T. (1974) Cowan and Steel's Manual for the identification of medical bacteria (2nd ed.), Cambridge. P. 33.

5. GoK [Govenment of Kerala]. (2017) Agricultural Statistics 2016-2017 [online].

6. Graff, A. and Conrad, R. (2005) Impact of flooding on soil bacterial communities associated with poplar (Populas sp.) trees. FEMS Microbiol. Ecol. 53(3): 401-415.

7. Hamdali, H., Bouizgarne, B., Hafidi, M., and Lebrihi, A. (2008) Screening for rock phosphate solubilizing actinomycetes from Moroccan phosphate mines. Appl. Soil Ecol. 38(1): 12-19. 
8. Hucker, G. J. and Conn, H. J. (1923) Comparison of various methods of Gram staining (preliminary report). Abstr. Bact. 6: 20-24.

9. Jackson, M. L. (1973) Soil Chemical Analysis. (Indian reprint, 1976), Prentice Hall of India, New Delhi, 478p.

10. Jeffries, P., Gianinazzi, S., Perotto, S., Turnau, K., and Barea, J.M. (2003) The contribution of arbuscular mycorrhizal fungi in sustainable maintenance of plant health and soil fertility. Biol. Fertil. Soils. 37: 1- 16.

11. Johnson, L. F. and Curl, E. A. (1972) Methods for research on the ecology of soil borne plant pathogens, Burgess, Minneapolis. J. Biotechnol. 7(8): 967-972.

12. Khamna, S., Yokota A., and Lumyong S. (2009) Actinomycetes isolated from medicinal plant rhizosphere soils: diversity and screening of antifungal compounds, indole-3-acetic acid and siderophore production. World J. Microbiol. Biotechnology. 25: 649-655

13. Li, Q., Chen, X., Jiang, Y., and Jiang, C. (2016) Morphological identification of actinobacteria. Intech open.

14. Merzaeva,O., Shirokikh, I., and Schwyn, B. (2016) Colonization of plant rhizosphere by Actinomycetes of different genera. Microbiol. 75: 226-230.

15. Nafiz, A., Raklami, A., Bechtaoui, N., Khalloufi, F. E., and Alaoui, A. E. (2019) Actinobacteria from extreme niches in Morocco and their plant growth promoting potentials. Diversity. 11: 139.

16. Nguyen, C., Yan, W., Le Tacon, F., and Lapeyrie, F., (1992) Genetic variability of phosphate solubilizing activity by monokaryotic and dikaryotic mycelia of tht ectomycorrhizal fungus Laccaria bicolor (Maire) PD Orton. Plant and Soil. 143(2): 193-199.

17. Olsen, S. R., Kemper, W. D., and Jackson, R. D. (1962) Phosphate diffusion to plant roots. Soil Sci. Soc. Am. J. 26(3): 222-227.

18. Panhwar, Q. A., Othman, R., Rahman, Z. A, Meon, S., and Ismail M. R. (2012) Isolation and characterization of phosphatesolubilizing bacteria from aerobic rice. Afr. J. Biotechnol.11:2711-2719.

19. Prada-Salcedo, L. D., Prieto, C., and Franco-Correa, M. (2014) Screening phosphate solubilizing actinobacteria isolated from rhizosphere of wild plants from the Eastern Cordillera of the Colombian Andes. Afr. J. Microbiol. Res. 8(8): 732-742.

20. Strzelczyk, A. B. (1981) Microbial biodeterioration: stone. In: Rose AH (ed.), Economic Microbiol. 6: 62-80.

21. Suksaaid, P., Pathom-aree, W., and Duangmal, K. (2017) Diversity and plant growth promoting activities of actinomycetes from mangroves. Chiang Mai. J. Sci. 44(4): 1210-1223.

22. Suzuki, S. I., Yamamoto, K., Okuda, T., Nishio, M., Nakanishi, N. and Komatsubara, S. (2000) Selective isolation and distribution of Actinomadura rugatobispora strains in soil Actinomycetol. 14:27-33.

23. Takizawa, M., Colwell, R. R. and Hill, T. R. (1993) Isolation and Diversity of Actinomycetes in the Chesapeake Bay. Appl. Environ. Microbiol. 59: 997-1002.

24. Taylor, W. I. and Achanzar, D. (1972) Catalase test as an aid to the identification of Enterobacteriaceae. J. Appl. Microbiol. 24:58-61.

25. Thampi, A. and Bhai, R. S. (2017) Rhizosphere actinobacteria for combating Phtophthora capsica and Sclerotium rolfsii, the major soil borne pathogens of black pepper. Biol. Cont. 109: 1-13.

26. Venkatakrishnan, S. S., Sudalayandy, R. S., and Savariappan, A. R. (2004) Assessing in vitro solubilization potential of different zinc solubilizing bacterial (ZSB) strains. Braz. J. Microbiol. 35: 121-125.
27. Vyawahare, S. S., Kamble, K. D., Waghmare. V. D., and Kamble L. H. (2015) Characterization of actinomycetes for some industrially important enzymes. Trends Biotech. Res. 2(2) 23200421. 